\title{
Caracterização físico-química dos efluentes de uma indústria de laticínios
}

\author{
Thayana Caroline Fontes Figueiredo1; (Graduanda em Química da Universidade do Estado do \\ Rio Grande do Norte - UERN) \\ Luiz Di Souza²; (Prof. Do DQ e do PPGCN da Universidade do Estado do Rio Grande do Norte - \\ UERN) \\ Rafael Batista de Oliveira3; (Prof. Da Universidade Federal Rural do Semi-Árido - UFERSA) \\ Sandra Maria Campos Alves33; (Prof. Da Universidade Federal Rural do Semi-Árido - UFERSA) \\ Adriana Paula Batista dos Santos4; (Doutoranda da Universidade do Federal do Rio Grande do \\ Norte - UFRN) \\ Email: thayanacarol2009@hotmail.com
}

\section{Resumo:}

A água é o bem mais precioso que existe, de forma que sem ela não conseguimos sobreviver. Segundo as estatísticas, $70 \%$ da superfície do planeta é constituída de água. Dessa água toda, o maior volume é de água salgada e somente $2,5 \%$ de água é doce. Desses $2,5 \%$, quase $98 \%$ estão "escondidos" na forma de água subterrânea. Apesar dessa grande quantidade, a maioria da água está poluída ou contaminada, além de se encontrar muito mal distribuída geograficamente, estando em menor quantidade nas regiões mais populosas. Assim um grande desafio desse milênio é descobrir formas de usar a água de modo racional e inteligente, economizando a mesma para que não falte no futuro.

Apesar de ser uma atividade econômica e socialmente importante, o setor de laticínios devem ter os seus efluentes tratados para não contribuírem com o aumento da poluição hídrica, o que ocorrerá se forem lançados nos recursos hídricos sem serem previamente tratados. Os efluentes gerados em indústrias lácteas possuem elevados teores de matéria orgânica, gorduras, sólidos suspensos e nutrientes, tendo que ser tratados adequadamente antes do descarte. As disposições inadequadas destas águas causam danos como a salinidade, sodicidade, alteração do $\mathrm{pH}$, entre outros e podem causar a contaminação dos recursos hídricos. O objetivo do trabalho foi avaliar a eficiência do tratamento dos efluentes realizados por uma indústria de laticínios via análise dos parâmetros físico-químicos previstos para descarte de efluentes padronizados na legislação. O afluente lácteo que foi analisado na saída foi submetido a um tratamento preliminar/secundário composto por gradeamento e caixa de gordura, seguido por lagoa aerada de mistura. Os resultados mostram que o tratamento feito não está sendo eficiente e que os parâmetros, RST, $\mathrm{DBO}_{5}$, Fosfato e TOG deixam o setor de tratamento muito acima dos limites permitidos. Desta forma conluiu-se que o seu descarte nos recursos hídricos é prejudicial ao meio ambiente e está contaminando os recursos hídricos.

Palavras-chaves: Indústria láctea; poluição; contaminação; tratamento de efluentes. 


\section{I ntrodução}

A água é o bem mais precioso que existe, de forma que sem ela não conseguimos sobreviver. Segundo as estatísticas, $70 \%$ da superfície doplaneta constituída de água. Dessa água toda, o maior volume é de água salgada e somente $2,5 \%$ de água doce e, desses $2,5 \%$, quase $98 \%$ estão “escondidos” na forma de água subterrânea (REBOUÇAS E TUNDISI, 1999). Apesar dessa grande quantidade, a maioria da água esta poluída ou contaminada, além de se encontrar muito mal distribuída geograficamente, estando em menor quantidadesnas regiões mais populosas. Assim o grande desafio desse milênio é descobrir formas de usar a água de modo racional e inteligente, economizando a mesma para que não falte no futuro.

Apesar da importância da água e de sua eminente falta, o homem continuacontribuindo para a poluição dos rios, lagos e destruindo as nascentes. Um dos problemas que causa essa poluição/contaminação é a falta de tratamento para os esgotos domésticos e industriais (Benetti e Bidone 1995). Os quais introduzem na água espécies químicas como sulfatos $\left(\mathrm{SO}_{2}{ }^{2-}\right)$, fosfatos $\left(\mathrm{PO}_{4}{ }^{-}\right)$, cloretos $\left(\mathrm{Cl}^{-}\right)$, óleos graxas (TOG) e metais pesados, substâncias que alteram as suas características físico-químicas deteriorando a qualidade.

Essa problemática vem causando preocupação e como conseqüência refletindo em leis que cobram o tratamento dos efluentes e resíduos, os quais devem atingir qualidade suficiente para serem descartados adequadamente, de forma a garantir o equilíbrio ambiental e proteger o meio ambiente de possíveis impactos ambientais.

Apesar de ser uma atividade economicamente e socialmente importante, o setor de laticínios devem ter os seus efluentes tratados para não contribuírem com o aumento da poluição hídrica.

O ânion Sulfato $\left(\mathrm{SO}_{4}{ }^{2-}\right)$ é um dos íons que é mais abundante na natureza, ele surge nas águas subterrâneas através da dissolução de solos e rochas, como o gesso $\left(\mathrm{CaSO}_{4}\right)$ e o sulfato de magnésio $\left(\mathrm{MgSO}_{4}\right)$. Nas águas de abastecimento publico, o sulfato deve ser controlado, pois pode causar efeito laxante. Muitos países recomendam como limite máximo de sulfato em efluentes e em água para diversos usos, uma faixa de 250 a $500 \mathrm{mg} / \mathrm{L}$ (FERREIRA et al., 2011) e a resolução 357 do CONAMA (Brasil, 2005) prevê para águas da classe II o limite máximo de $250 \mathrm{mg} / \mathrm{L}$.

A presença de $\mathrm{PO}_{4}{ }^{2-}$ pode ser encontrada, em alta concentração em adubos e fertilizantes usados na agricultura. Esse poluente orgânico constitui nutrientes para as plantas aquáticas, especialmente as algas. $\mathrm{O}$ fósforo ocorre em águas naturais e em efluentes geralmente na forma de fosfatos de vários tipos (ortofosfatos, piro e metafosfatos ou polifosfatos), bem como fosfatos orgânicos (WETZEL 1993). Com relação aos limites permitidos, a resolução ${ }^{\circ}$ 357/2005 estabelece limite, para a concentração de fósforo total, que varia entre 0,02 e 0,015 $\mathrm{mg} / \mathrm{L}$, dependendo do ambiente e da classe do corpo de água (PINHEIRO et al., 2013).

Os parâmetros Dureza e Alcalinidade estão muito relacionados ao ambiente em que a água se encontra e estão diretamente relacionados com o solo. É possível relacionar o valor da alcalinidade com o parâmetro de dureza, uma vez que os cátions mais comuns atrelados aos ânions causadores de alcalinidade são o cálcio $\left(\mathrm{Ca}^{+2}\right)$ e o magnésio $\left(\mathrm{Mg}^{+2}\right)$, que também estão relacionados com a dureza da água (APHA 2005). Os cátions ferro, manganês, estrôncio e alumínio também estão associados, à dureza só que se encontra em menor escala e na determinação de dureza são considerados como sefossem carbonatos. Dependendo do ânion com o qual ela está associada, a dureza pode ser classificada como dureza carbonato ou dureza não carbonato. De acordo com o grau de dureza, expresso em mg/L a água pode ser classificada em:

- Mole ou branda: < 50 mg.L $\mathrm{CaCO}_{3}$

- Dureza moderada: entre 50 e 150 mg.L $\mathrm{CaCO}_{3}$ 
- Dura: entre 150 e 300 mg.L $\mathrm{CaCO}_{3}$

- $\quad$ Muito dura: > 300 mg.L $\mathrm{CaCO}_{3}$

Há evidência de que a ingestão de águas duras contribui para uma menorincidência de doenças cardiovasculares (MORAIS et al., 2008).

A alcalinidade de uma água é a capacidade em neutralizar ácidos, servindo para expressar a capacidade de tamponamento da água e sua condição em resistir a mudança do $\mathrm{pH}$. As substâncias mais comuns encontradas em águas de superfície causadoras de alcalinidade são os carbonatos $\left(\mathrm{CO}_{3}{ }^{+2}\right)$, bicarbonatos $\left(\mathrm{HCO}_{3}^{-}\right)$e hidróxidos $\left(\mathrm{OH}^{-}\right)$e de acordo com o $\mathrm{pH}$, estas três formas de alcalinidade da água se encontram, distribuídas da seguinte forma:

$\mathrm{pH}>9$,4: Hidróxidos e Carbonatos;

$8,3<\mathrm{pH}<9,4$ : Carbonatos e Bicarbonatos;

4,4 $<\mathrm{pH}<8,3$ : Apenas Bicarbonatos.

As águas naturais, em sua maioria, apresentam valores de alcalinidade na faixa de 30 a $500 \mathrm{mg} / \mathrm{L}$ de $\mathrm{CaCO}_{3}$ (MORAIS et al., 2008).

A salinidade mede a quantidade de sais presentes e dissolvidos nas águas de reservatórios ou lagos. Este parâmetro encontra-se com valores maiores no verão, devido à evaporação da água, sendo menor no inverno, devido ás chuvas que diluem a água e diminui o mesmo.

O cloreto $\left(\mathrm{Cl}^{-}\right)$é um dos íons mais comuns em águas naturais, em esgotos domésticos e em despejos industriais. Mesmo em altas concentrações o cloreto não é prejudicial á saúde humana nem às canalizações, mas baixas concentrações $(250 \mathrm{ppm})$ são recomendadas para 0 uso agrícola (BRASIL, 2005)) porque podem causar estresse salino das plantas e salinização do solo.

Efluentes industriais de óleo comestíveis, laticínios, matadouro e frigoríficos contribuem para a geração de efluentes oleosos (SAWYER et al,. 1994). O petróleo tem grande significado para a economia mundial, mas também representa um problema para o meio ambiente, devido à contaminação da água com óleo. A presença de óleos e graxas impede a entrada de luz na água, impedindo a realização de fotossíntese pelas algas e alterando todo o ecossistema aquático, assim aanálise de óleos e graxas (TOG) é utilizada como parâmetro de qualidade de água. De acordo com a legislação federal, a resolução $n^{\circ} 20$ do CONAMA, os limites máximos de descartes de óleos em efluentesé de $50 \mathrm{mg} / \mathrm{L}$ para óleos de origem vegetal e de $20 \mathrm{mg} / \mathrm{L}$ para óleos minerais (KATO et al., 1983).

Resíduos sólidos são todos os materiais presentes nos despejos domésticos ou industriais que permanecem sólidos após a secagem ou calcinação a uma temperatura preestabelecida por um tempo fixo.

Os efluentes gerados em indústrias lácteas possuem elevados teores de matéria orgânica, gorduras, sólidos suspensos e nutrientes, tendo que ser tratado adequadamente antes do descarte. A sua disposição inadequada no solo causa danos como a salinização, sodicização, alteração no $\mathrm{pH}$, entre outros e se descartados em recursos hídricos podem causar a contaminação dos mesmos. O objetivo do trabalho foi avaliar a eficiência do tratamento dos efluentes realizado por uma indústria de laticínios via análise dos parâmetros físico-químicos, especialmente, osprevistos para descarte de efluentes na legislação.

\section{Métodos e materiais}

As amostras de efluentes de laticínios na entrada e na saída da estação de tratamento foram coletadas em frascos âmbar, conservadas em gelo ou quimicamente e imediatamente transportadas para o laboratório de Catálise, Ambientes e Naturais - LACAM da Universidade do Estado do Rio Grande do Norte - UERN. O afluente lácteo que foi analisado na saída foi submetido a um tratamento preliminar/secundário composto por gradeamento e caixa de gordura, seguido por lagoa aerada de mistura (Oliveira et al., 2014).

A caracterização físico-química da água residuária do laticínio foi realizada por meio da coleta de três amostras compostas no período de novembro a dezembro de 2013. Cada amostra 
composta foi obtida de amostras simples coletadas ás 8:00h, 11:00h, e 14:00h, em dois pontos dos sistema de tratamento (P1 - efluente coletado a montante do gradeamento/caixa de gordura e P2 efluente coleta a jusante da lagoa aerada). A lagoa apresenta dois aeradores com densidade de potencia de $30 \mathrm{~W} / \mathrm{m}^{3}$ e potencia de $4 \mathrm{CV}$. Após a coleta as amostras foram preservadas em caixas isotérmicas com gelo até sua entrada Laboratório de Catálise, Ambientes e Materiais LACAM da Universidade do Estado do Rio Grande do Norte - UERN. As análises realizadas foram a determinação de Sulfato, $\mathrm{PO}_{4}$, Dureza, Salinidade, Amônia, Alcalinidade, $\mathrm{DQO}, \mathrm{DBO}_{5}$, Cloreto, TOG E RST, de acordo com os procedimentos descritos na literatura (APHA, 2005). Para todos os parâmetros as amostras foram analisadas em duplicata os resultados foram obtido em ppm.

As análises de sulfato, amônia e fosfato foram feitas num espectrofotômetro de UV-vis da Marca Shimadzu modelo UV mini 1240 via quantificação com curva padrão, as análises de Salinidade, Dureza, $\mathrm{DBO}_{5}, \mathrm{DQO}$, Alcalinidade e Cloreto foram feitas volumetricamente e as análises de RST e TOG foram feitas gravimetricamente.

\section{Resultados e Discussão}

A Tabela 1 mostra os resultados obtidos para todos os parâmetros na entrada e na saída da estação de tratamento da indústria de laticínios.

Tabela - 1: Resultados dos parâmetros analisados na entrada e na saída da estação de tratamento.

\begin{tabular}{lcccc}
\hline Amostras/Parâmetros & Entrada & Saída & $\begin{array}{l}\text { Limites } \\
\text { CONAMA 357 }\end{array}$ & $\begin{array}{l}\text { Limites } \\
\text { CONAMA 430 }\end{array}$ \\
\hline RST/mg/L & 4.754 & 3.506 & 1000 & - \\
TOG/ppm & 2.225 & 976 & - & 50 \\
Cloreto/ppm & 182 & 70 & 250 & - \\
\hline Alcalinidade/ppm & 112 & 44 & - & - \\
\hline Amônia/ppm & 2,8236 & 0,5479 & - & 20 \\
Salinidade/ppm & 299.94 & 115.36 & - & - \\
Dureza/ppm & 283,148 & 131,508 & - & - \\
PO4/ppm & 982,950 & 861,110 & 0.02 a 0.015 & - \\
Sulfato/ppm & 0,4868 & 0,1529 & 250 & 120 ppm ou $60 \%$ \\
DBO $/$ redução
\end{tabular}

Os resultados mostram que para os teores de nitrogênio amoniacal, cloreto e sulfato os efluentes tratados não apresentam problemas estando abaixo dos valores permitidos para descarte.

O tratamento promoveu uma boa redução no teor de resíduos totais (RST), óleos e graxas (TOG) e fosfato $\left(\mathrm{PO}_{4}{ }^{-}\right)$, mas mesmo assim os teores destas substâncias se encontram muito acima do limite permitidos na legislação para descarte destes efluentes como mostram os gráficos 1 , 2 e 3 dessas variáveis. 


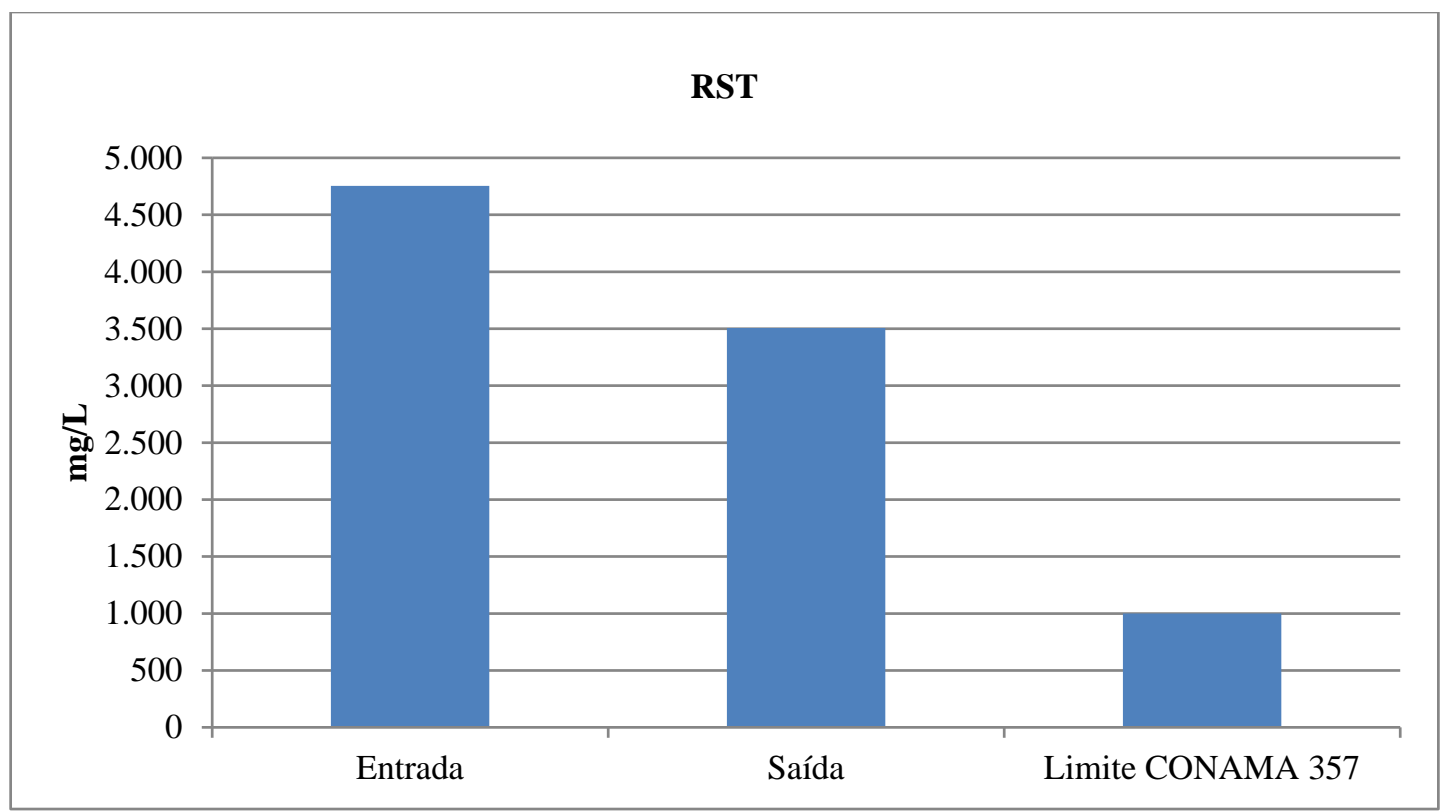

Gráfico - 1: Teores de RST na entrada e saída da estação de tratamento da indústria e limite previsto na legislação.

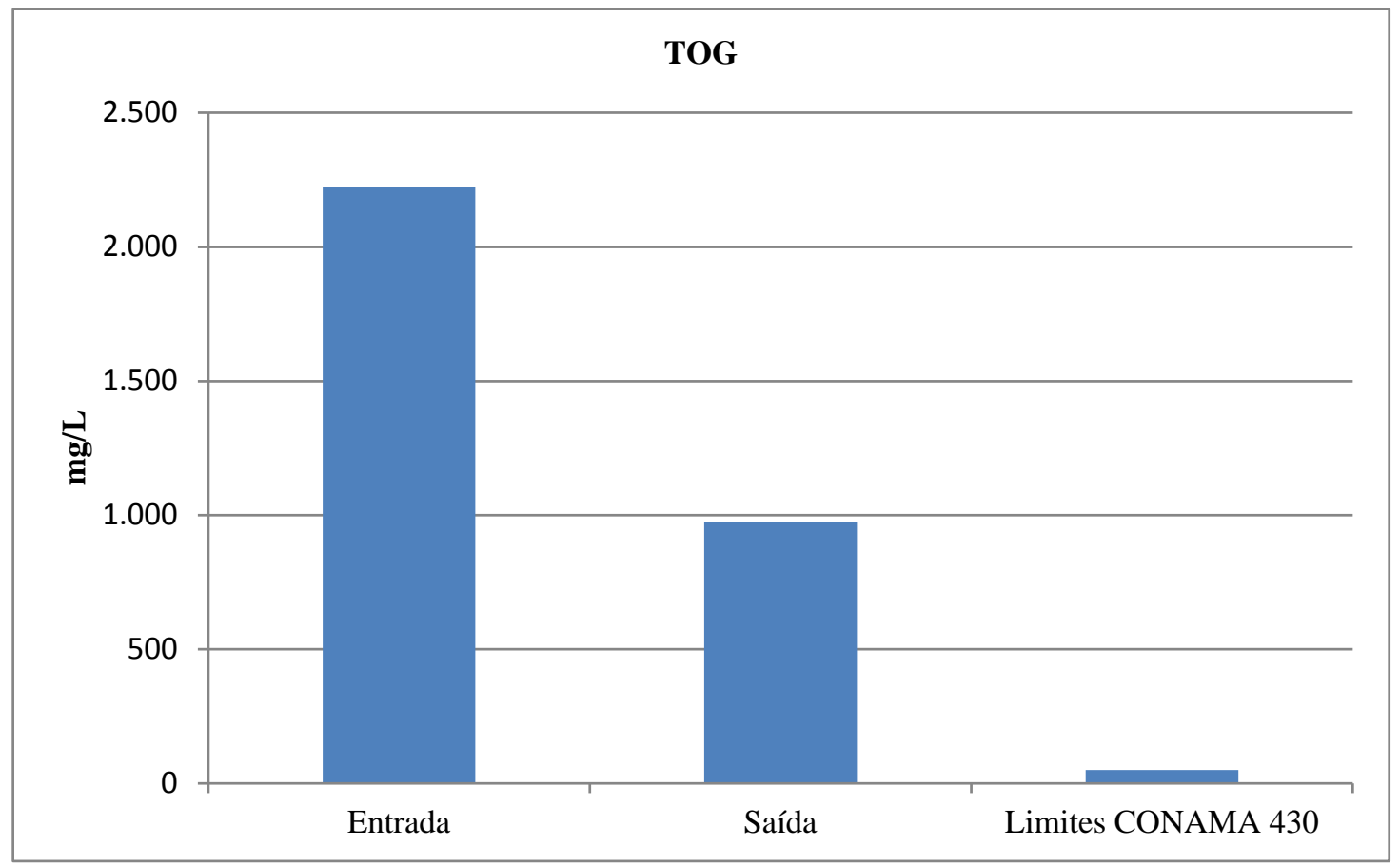

Gráfico - 2: Teores de TOG na entrada e saída da estação de tratamento da indústria e limite previsto na legislação. 


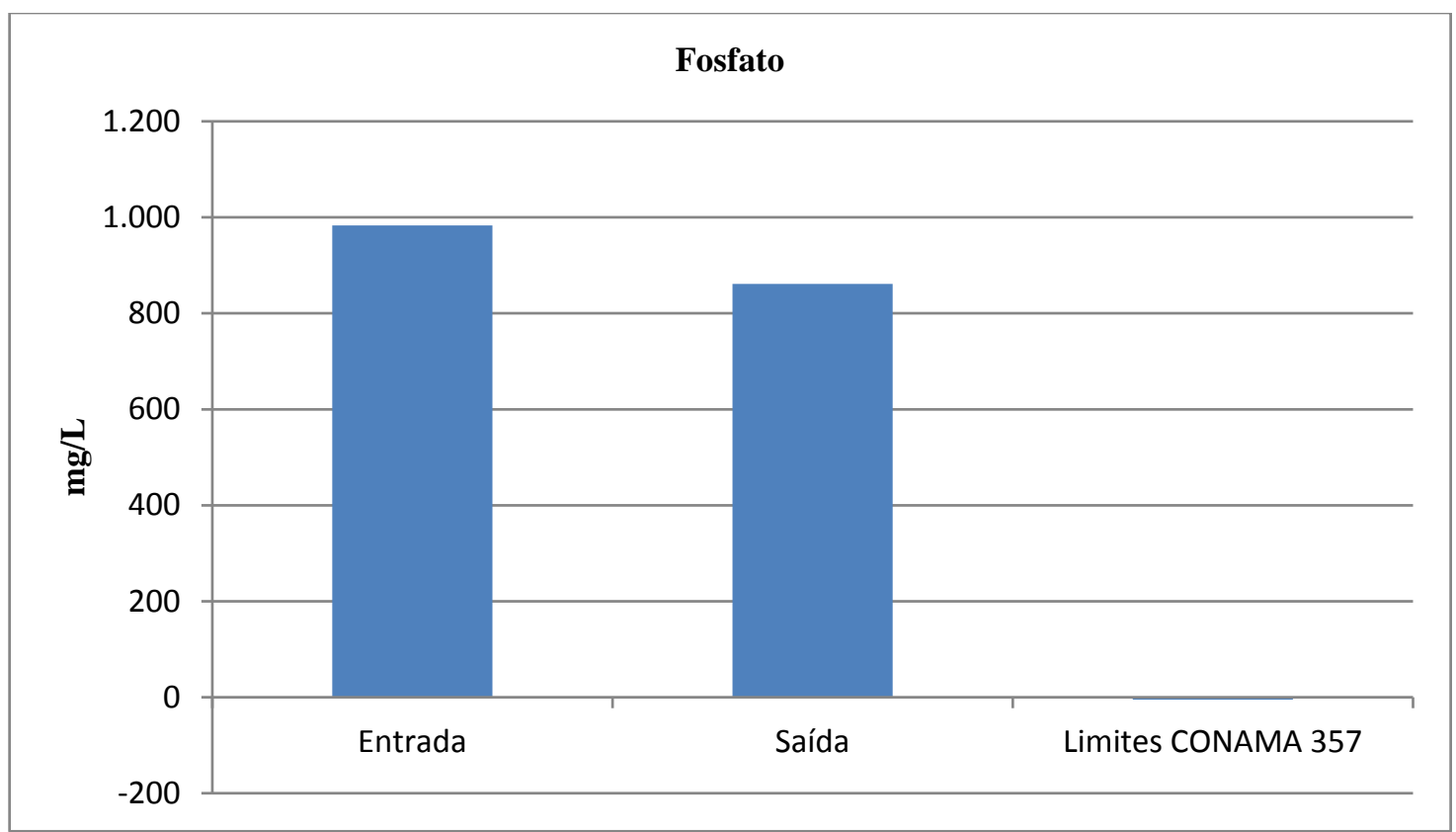

Gráfico - 3: Teores de fosfatos na entrada e saída da estação de tratamento da indústria e limite previsto na legislação.

A carga de RST diminui em 25\% resultado bem próximo ao obtido por Campos e et al., (2004) usando um reator UASB.

Os parâmetros alcalinidade, salinidade e dureza não têm limites estabelecidos na legislação e mostraram redução compatível com a redução de resíduos sólidos totais e $\mathrm{DBO}_{5}$ observadas, como pode ser visto no gráfico 4 para o caso especifico da dureza.

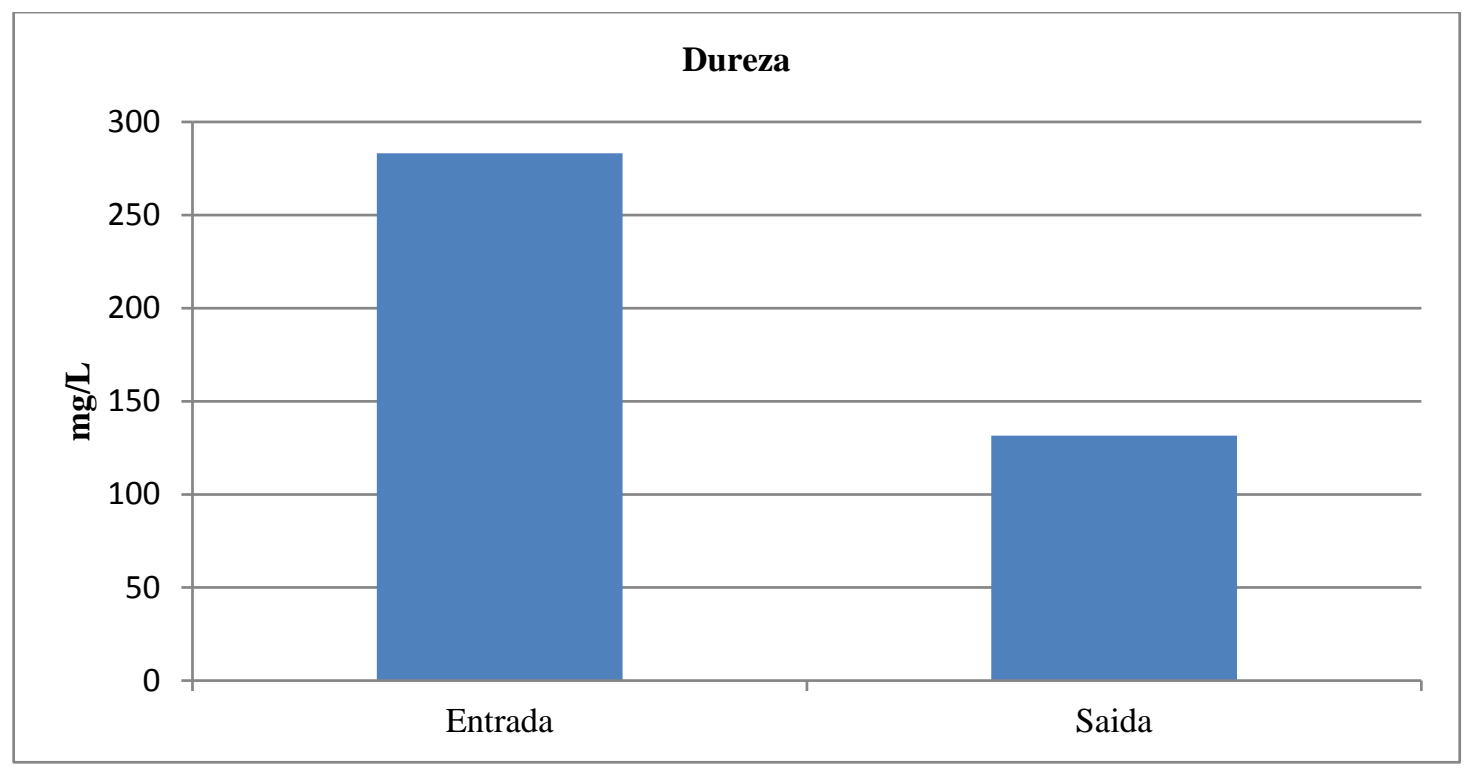

Gráfico - 4: Dureza na entrada e saída da estação de tratamento da indústria e limite previsto na legislação. 
O sistema de tratamento promoveu 56,52\% de redução na concentração da DQO (variação de 1632,20 (mg L-1) na entrada para 709,70 (mg l-1) na saída) e redução de 79,14\% na concentração da $\mathrm{DBO}_{5}$, com variação de 912,80 (mg L-1) na entrada para 190,40 (mg L-1) na saída após tratamento como mostra o gráfico 5. De acordo com a Resolução CONAMA 430/2011, o efluente de laticínios tratado está acima do limite de 120 (mg L-1) de carga de $\mathrm{DBO}_{5}$ para lançamentos em corpos hídricos, mas atinge o limite de tratamento exigido pela lagoa que é de redução de no mínimo $60 \%$.

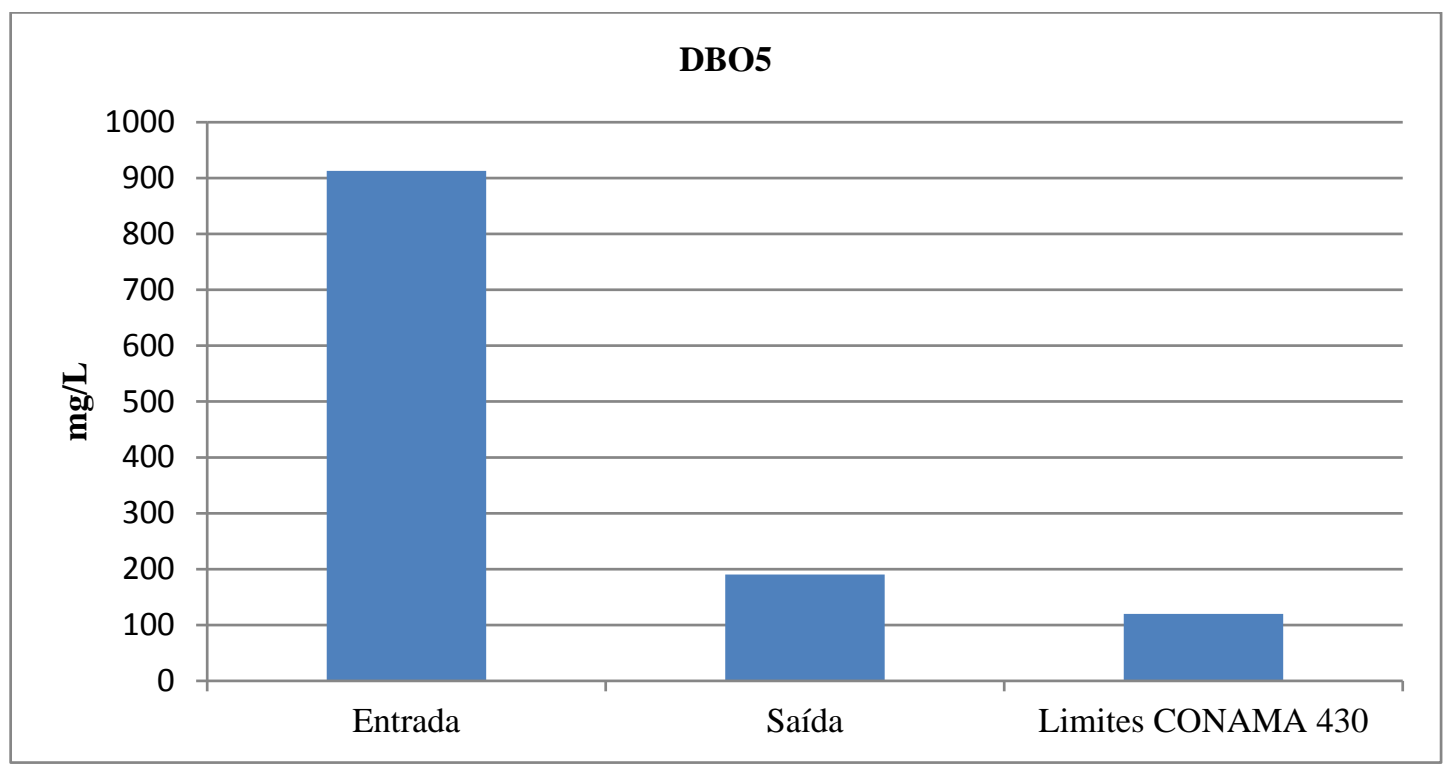

Gráfico - 5: Concentração de $\mathrm{DBO}_{5}$ na entrada e saída da estação de tratamento da indústria e limite previsto na legislação.

Machado et al. (2002) afirmam que a relação entre DBO/DQO para efluentes lácteos se encontram entre 0,50 e 0,70, constando que valores fora dessa faixa são indicadores de efluentes de natureza incomum. Janczukowiczet al. (2008) caracterizaram os efluentes gerados em diversos setores de uma mesma indústria de laticínios (recebimento de leite, processamento de leite, produção de creme, manteiga e queijo e para a junção de todos os efluentes). Os autores observaram elevadas variações nas concentrações de DQO, DBO e sólidos suspensos na entrada e saída do tratamento.

Por outro lado, diversos trabalhos mostram que os recursos hídricos da região, principalmente o rio Apodi/Mossoró já se encontra bastante poluído (Castro et al. 2007, 2011, 2012 A e B e 2013), Oliveira, 2011 e Silva e Souza (2013), sendo que o descarte de efluentes poluídos nele deve ser evitado para a sua preservação e , também, do seu entorno. Deve-se ressaltar que o não desta recomendação legal pode resultar em águas que não atendem a qualidade necessária para os seus devidos usos, bem como a perda de atividades econômicas importantes que são realizadas com suas águas como a pesca, a pecuária (dessedentação de animais) e a irrigação.

\section{Conclusão}

Com Base nos resultados pode-se incluir que o sistema de tratamento utilizado pela empresa não está sendo apropriado para tornar os efluentes adequados para serem descartados nos recursos hídricos. Os valores de RST, TOG, $\mathrm{PO}_{4}$ e $\mathrm{DBO}_{5}$ continuam fora dos limites permitidos 
e o seu descarte pode acarretar prejuízos ao rio Apodi/Mossoró, sendo necessário que o sistema seja ajustado ou complementado para evitar problemas ambientais.

\title{
5. Agradecimentos
}

Agradecemos ao projeto água azul pela ajuda financeira e pelas coletas realizadas, ao laboratório de catálise, ambiente e materiais (LACAM) e a Universidade do Estado do Rio Grande do Norte - UERN.

\section{Physicochemical characterization of the effluents from a dairy industry}

\begin{abstract}
:
Water is the most precious asset that exists, so that without it we could not survive. According to statistics, $70 \%$ of the Earth's surface is made up of water. This water, the largest volume of salt water and only $2.5 \%$ is fresh water. Of these $2.5 \%$, almost $98 \%$ are hidden in the form of groundwater. Despite this large amount, most of the water is polluted or contaminated, as well as being very poorly distributed geographically, being a lesser amount in the most populous regions. So a big challenge of this Millennium is to find ways to use water so rational and intelligent, saving the same so don't miss in the future.

Despite being an economic activity and socially important, the dairy sector should have its treated effluent to not contribute with increased water pollution, what will happen if they are released in water resources without being previously treated. The wastewater generated in dairy industries have high levels of organic matter, suspended solids and nutrients, fats, having to be treated properly before disposal. The inadequate provisions in these waters cause damage such as salinity, sodicity, changing the $\mathrm{pH}$, among others and can cause the contamination of water resources. The objective of this work was to evaluate the efficiency of effluent treatment performed by a dairy industry via analysis of physical and chemical parameters provided for disposal of standardized effluent in legislation. The tributary that was analyzed in dairy output has been subjected to a preliminary/secondary treatment consisting of railing and fat box, followed by aerated lagoon. The results show that the treatment not being efficient and that the parameters, RST, Bod5, phosphate and TOG leave the treatment sector well above the limits allowed. In this way conluiu your disposal on water resources is harmful to the environment and are contaminating water resources.
\end{abstract}

Keywords: Dairy industry; pollution; contamination; treatment of effluents.

\section{Referências Bibliográficas}

Adilson Pinheiro, Vander Kaufmann, Danieli Schneiders,Daniela A. de Oliveira, Renata M. R. Albano. Concentrações e cargas de nitrato e fosfato na Bacia do Ribeirão Concórdia, Lontras, SC. Revista Brasileira de Engenharia Agrícola e Ambiental v.17, n.1, p.86-93, 2013.

Aldo da Cunha Rebouças e J. G. Tundisi -Agua doce do Brasil , Ed. Escrituras, 1999.

APHA. Standard Methods for examination of water and wasterwater. 21 ed. Washington, USA: American Public Health Association, 2005.

Benetti, A.; Bidone, F. O meio ambiente e os recursos hidricos. IN: TUCCI, C. E. M. Hidrologia: ciência e aplicação. Porto Alegre: Ed. da Universidade/UFRGS/ABRH, 1995. p. 669. 
BRUNO Christiano Silva Ferreira; ROSA Malena Fernandes Lima; VERSIANE Albis Leão. Remoção de sulfato de efluentes industriais por precipitação. EngSanitAmbient | v.16 n.4 | out/dez 2011 | 361-368.

CASTRO, S. S. L. ; OLIVEIRA, T. M. B. F. ; MORAIS, P. R. F. ; SOUZA, L.D.. Impact study of untreated domestic effluents discharge in the rivers through WQI: a real case in the Apodi/Mossoró basin. Química no Brasil. v. 5, p. 23-31, 2011.

CASTRO, S. S. L., SOUZA, L.D.; MARTINS, D. F. F.; OLIVEIRA, T. M. B. F.; BATISTA, R.S. Qualidade físico-química das águas da bacia do Rio Apodi/Mossoró. Química no Brasil, v.2, p.61 - 74, 2007.

CASTRO, SSL ; SOUZA, LUIZ Di ; Silva, L. M.. Monitoramento espaço temporal da qualidade das águas da bacia hidrográfica do rio Apodi/Mossoró - RN. Química no Brasil. 2012 A.

CASTRO, Suely Souza Leal de ; SOUZA, L.D. ou Souza, L. ; DANTAS, I. M. ; SILVA, G. H. G. ; CASTRO, R. S.. Sustainable Use of Water in Tropics and Subtropics: The Case of Apodi/Mossoró River Basin in the Brazilian Semi-Arid. Em: Carolina Bilibio; Oliver Hensel; Jeferson Francisco Selbach. (Org.). Sustainable Water Management in the Tropics and Subtropics - and Case studies in Brasil. 1ed.jaguarão. : Fundação Universidade Federal do Pampa, Unikassel, PGCult-UFMA. 2012 B.v. 3, p. 537-561.

CLÁUDIO Milton Montenegro Campos , FÁTIMA Aparecida Resende de Luiz , Cláudio Gouvêa Botelho , Leonardo Henrique Soares Damasceno - Avaliação da eficiência do reator uasb tratando efluente de laticínio sob diferentes cargas orgânicas. Ciênc. agrotec., Lavras, v. 28, n. 6, p. 1376-1384, nov./dez., 2004.

Brasil- CONAMA - Conselho Nacional do Meio Ambiente. Resolução n 357/05. Estabelece a classificação das águas doces, salobras e salinas do Território Nacional. Brasília, SEMA, 2005.

JANCZUKOWICZ, W.; ZIELIŃSKI, M.; DĘBOWSKI, M. Biodegradability evaluation of dairy effluents originated in selected sections of dairy production. Bioresource Technology, New York, v.99, n.10, p.4199-4205, 2008.

KATO, M.T., “Óleos e Graxas”. Curso Qualidade da Água, do Ar e do Solo. Escola de Engenharia Mauá, 1983.

MACHADO, R.M.G.; FREIRE, V.H.; SILVA, P.C.; FIGUERÊDO, D.V.; FERREIRA, P.E. Controle ambiental nas pequenas e médias indústrias de laticínios. 1 ed. Belo Horizonte: Segrac, 2002, 223p.

OLIVEIRA, J.F. ; Alves. S.M.C.; Batista, R.O. ; Lima, V.I. ; Souza, L. D. -avaliação de sistema de tratamento de laticínio e o efeito do efluente gerado nos atibutosfisico-químico de um argissolo vermelho, Revista Engenharia na agricultura, viçosa - MG, V.22 N.1, JANEIRO / FEVEREIRO 2014.

OLIVEIRA, T. M. B. F.; SOUZA, L. S.; CASTRO, S. S. L.; Dinâmica da série nitrogenada nas águas da bacia hidrográfica Apodi/Mossoró - RN - Brasil. Revista Eclética Química. v. 34, n. 3, 2009. Disponível em: <http://www.scielo.br/pdf/eq/v34n3/02.pdf>. Acesso em: 15 set. 2011.

PETERSON B. Moraes. Tratamento biológico de efluentes líquidos e tratamento físicoquímico de efluentes líquidos.UNICAMP, 2008. 
SAWYER, C.N., McCARTY, P.L. e PARKIN, G.F., “Chemistry for Environmental Engineers”. McGraw-Hill International Editions, Civil Engineering Series. 4th Ed., 1994.

SILVA A. G.; SOUZA L. D. Efeitos Antropicos e Sazonais na qualidade da água do rio do Carmo. Revista HOLOS, v. 5, p. 131. 2013.

WETZEL, R. G., 1993, Lisboa. Ed. Fundação Calouste Gulbenkian. 919p. ESTEVES, F.A. 1998. Fundamentos de limnologia. 1a. ed. Rio de Janeiro. 